\title{
Effects of a-tocopherol on hemolysis and oxidative stress markers on red blood cells in $\beta$-thalassemia major
}

\author{
Nora Sovira, MD¹, Munar Lubis, MD², Pustika Amalia Wahidiyat, MD, PhD ${ }^{3}$, Franciscus D. Suyatna, MD, PhD ${ }^{4}$, Djajadiman Gatot, \\ $\mathrm{MD}^{3}$, Saptawati Bardosono, MD, $\mathrm{PhD}^{5}$, Mohammad Sadikin, $\mathrm{MD}^{6}$ \\ ${ }^{1}$ Division of Pediatric Emergency \& Intensive Care, Department of Pediatrics, Faculty of Medicine, University of Syiah Kualal/Dr. Zainoel Abidin Hospital, Banda Aceh, \\ Indonesia; ${ }^{2}$ Division of Pediatric Emergency \& Intensive Care, Department of Pediatrics, Faculty of Medicine, University of Sumatera Utara/University of Sumatera \\ Utara Hospital, Medan, Indonesia; ${ }^{3}$ Division of Hematology Oncology, Department of Pediatrics, Departments of ${ }^{4}$ Pharmacology and Therapeutics, ${ }^{5}$ Nutrition, and \\ ${ }^{6}$ Biochemistry and Molecular Biology, Faculty of Medicine, University of Indonesia/Dr. Cipto Mangunkusumo Hospital, Jakarta, Indonesia
}

Background: The accumulation of unpaired $\alpha$-globin chains in patients with $\beta$-thalassemia major may clinically create ineffective erythropoiesis, hemolysis, and chronic anemia. Multiple blood transfusions and iron overload cause cellular oxidative damage. However, $\alpha$-tocopherol, an antioxidant, is a potent scavenger of lipid radicals in the membranes of red blood cells (RBCs) of patients with $\beta$-thalassemia major.

Purpose: To evaluate the effects of $\alpha$-tocopherol on hemolysis and oxidative stress markers on the $\mathrm{RBC}$ membranes of patients with $\beta$-thalassemia major.

Methods: Forty subjects included in this randomized controlled trial were allocated to the placebo and $\alpha$-tocopherol groups. Doses of $\alpha$-tocopherol were based on Institute of $\mathrm{Me}$ dicine recommendations: 4-8 years old, $200 \mathrm{mg} /$ day; 9-13 years old, $400 \mathrm{mg} /$ day; $14-18$ years old, $600 \mathrm{mg} /$ day. Hemolysis, oxidative stress, and antioxidant variables were evaluated before and after 4 -week $\alpha$-tocopherol or placebo treatment, performed before blood transfusions.

Results: Significant enhancements in plasma haptoglobin were noted in the $\alpha$-tocopherol group $(3.01 \mathrm{mg} / \mathrm{dL}$; range, $0.60-42.42 \mathrm{mg} / \mathrm{dL} ; P=0.021$ ). However, there was no significant intergroup difference in osmotic fragility test results; hemopexin, malondialdehyde, reduced glutathione (GSH), or oxidized glutathione (GSSG) levels; or GSH/GSSG ratio.

Conclusion: Use of $\alpha$-tocopherol could indirectly improve hemolysis and haptoglobin levels. However, it played no significant role in oxidative stress or as an endogen antioxidant marker in $\beta$-thalassemia major.

Key words: $\alpha$-Tocopherol, Hemolysis, Oxidative stress, $\beta$ Thalassemia major

\section{Key message}

Questions: Is the $\alpha$-tocopherol as an exogenous antioxidant supplementation effective in improving hemolysis and oxida- tive stress on $\beta$-thalassemia major?

Finding: We found significant enhancements in plasma haptoglobin were noted in the $\alpha$-tocopherol group $(3.01 \mathrm{mg} / \mathrm{dL}$; range, $0.60-42.42 \mathrm{mg} / \mathrm{dL} ; P=0.021$ ).

Meaning: The $\alpha$-tocopherol can improve hemolysis by increasing the haptoglobin level as hemolysis marker.

\section{Introduction}

Thalassemia is a genetic disease in the form of a disordered synthesis of the globin chain. The number of patients with thalassemia major throughout Indonesia in 2019 was 10.531, and 666 were registered at the Thalassemia Center of the Department of Pediatrics, Faculty of Medicine, University of Indonesia/Cipto Mangunkusumo Hospital (CMH), Jakarta, in 2018, and the number of new patients was around 51 patients. Beta thalassemia major is chronic hemolytic anemia and an autosomal recessive hereditary due to the complete deficiency in the synthesis of $\beta$-globin chains. Beta thalassemia major typically requires lifelong blood transfusions. ${ }^{1,2)}$ The $\alpha$-chain aggregates could produce reactive oxygen species, leading to oxidative stressinduced red blood cell (RBC) senescence. ${ }^{3)}$

The basic clinical symptom of $\beta$-thalassemia major is chronic anemia, which reduces the number of RBCs and hemoglobin $(\mathrm{Hb})$ content, resulted from hemolysis and a deficiency in $\mathrm{Hb}$ production When RBCs are destroyed within the vascular com. partment, $\mathrm{Hb}$ escapes into the plasma, dimerizes, and is rapidly bound by the serum protein haptoglobin ( $\mathrm{Hp})$. Depending on the extent and frequency of hemolysis, Hp may deplete, and free $\mathrm{Hb}$ leads to heme synthesis in plasma. Heme is rapidly transferred to hemopexin $(\mathrm{Hx})$, the plasma protein with the highest binding affinity for heme.,5) The measurements of $\mathrm{Hp}$ and $\mathrm{Hx}$ serum are used as hemolysis markers. ${ }^{6,7}$ Osmotic fragility tests can also measure the lysis of RBC as a function of

Corresponding author: Nora Sovira, MD. Division of Pediatric Emergency \& Intensive Care, Department of Pediatrics, Faculty of Medicine, University of Syiah Kuala, Kopelma Darussalam, Banda Aceh 23111, Indonesia

凶E-mail: drviera79@yahoo.co.uk, https://orcid.org/0000-0002-7258-9913

Received: 20 May, 2019, Revised: 10 December, 2019, Accepted: 18 February, 2020

This is an open-access article distributed under the terms of the Creative Commons Attribution Non-Commercial License (http://creativecommons.org/licenses/bync/4.0/) which permits unrestricted non-commercial use, distribution, and reproduction in any medium, provided the original work is properly cited.

Copyright (c) 2020 by The Korean Pediatric Society 


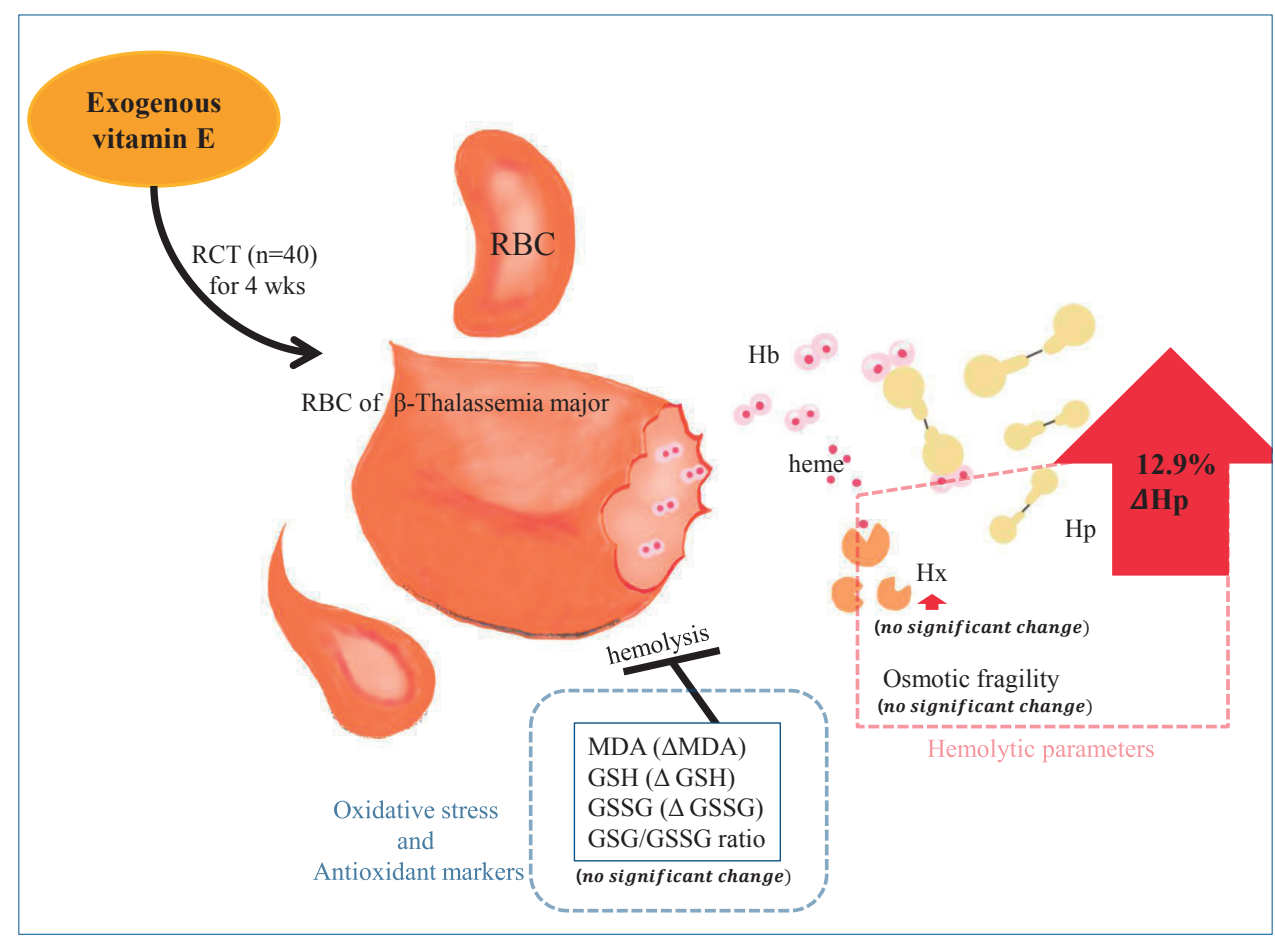

Graphical abstract. Effect of a-tocopherol on hemolysis and oxidative stress markers on the red blood cell (RBC) membranes of patients with $\beta$-thalassemia major. Hp, haptoglobin; $\mathrm{Hx}$, hematopexin; MDA, malondialdehyde; GSH, reduced Glutathione; GSSG, oxidized glutathione.

osmotic stress. ${ }^{8)}$

Data have shown that the indicated lipid of membrane peroxidation in the RBCs of patients with $\beta$-thalassemia major is induced by oxidative stress. $\left.{ }^{9}\right)$ Reduced glutathione (GSH) is one of the most effective endogenous antioxidant mechanism, turning oxidized to oxidized glutathione (GSSG) and recycling it to its reduced form by glutathione reductase (GR). ${ }^{10,11)}$

Consuming vitamin $\mathrm{E}$ ( $\alpha$-tocopherol) as an antioxidant can prevent some of the damage in the thalassemia RBC membrane. 9,12) It has been postulated that the low serum of $\alpha$-tocopherol can be caused by the secondary consumption of the antioxidant in $\beta$-thalassemia major patients. ${ }^{13)}$ There are different guidelines on antioxidant supplementation for the $\beta$-thalassemia major in children. The Thalassemia International Federation (TIF), did not recommend, supplementation of $\alpha$-tocopherol for children with $\beta$-thalassemia major. ${ }^{14)}$ The standard care of thalassemia from Oakland Hospital for the $\alpha$-tocopherol antioxidant supplement suggested an evaluation of annual nutritional laboratory testing of $\alpha$-tocopherol. ${ }^{15)}$ The Indonesian Pediatric Society Coordination work unit from the Hematology Oncology Division recommended $\alpha$-tocopherol with the doses of $200 \mathrm{mg}$ daily for children below 5 years old, and $200 \mathrm{mg}$ twice daily for children aged 5 years old as the antioxidant supplementation in children with $\beta$-thalassemia major. ${ }^{16)}$ This study, evaluated the efficacy of the $\alpha$-tocopherol on hemolysis and oxidative stress in RBCs membrane of $\beta$-thalassemia major patients.

\section{Methods}

This study was a double-blind, randomized clinical trial. The subjects were $\beta$-thalassemia major patients hospitalized in thalassemia ward at CMH between December 2016 and July 2017.

\section{Study participants}

The inclusion criteria were the children aged $5-18$ years old who received transfusions in once a month and iron chelation, with no other hematologic disorders, and do not consume any other antioxidants or herbal supplements. Exclusion criteria were $\beta$-thalassemia major patients with the acute or chronic infection including hepatitis B or hepatitis $\mathrm{C}$, splenectomy, liver failure and abnormality level of lipid test.

\section{Study groups and randomization}

The sample size was determined by independent sample $t$ test for examining a difference between two means. Subjects were selected by the consecutive sampling of $\beta$-thalassemia major patients and were randomized using block allocation. The patients were randomized into two groups, the placebo and the $\alpha$-tocopherol group.

\section{Intervention}

The $\alpha$-tocopherol dosage age groups were adjusted by the body weight, as suggested based on tolerable upper supplementary intake level by the Institute of Medicine. The range of dosage for children aged $5-8$ years old is $200 \mathrm{mg} /$ day, $9-13$ years old is $400 \mathrm{mg} /$ day and $14-18$ years old is $600 \mathrm{mg} /$ day for four weeks. 
The supplementation of the $\alpha$-tocopherol and placebo were prepared by $\mathrm{CMH}$ Pharmacy division. The $\alpha$-tocopherol supplement therapy started immediately after the subjects had finished the regular blood transfusion. Informed consent was obtained from all parents/participants, and this study was approved by the Ethical Committee of the Medical Research, University of Indonesia (No 1050/UN2.F1/Ethic/2015).

\section{Clinical procedure and laboratory investigation}

Blood samples were collected from each subject just before they received their regular blood transfusions. Clinical laboratory examinations, including complete blood count, alanine transaminase (ALT), total cholesterol, iron profile (serum ferritin, serum iron), and all other hematological parameters tests were performed at the clinical pathology laboratory of $\mathrm{CMH}$.

Hemolysis markers ( $\mathrm{Hp}$ and $\mathrm{Hx}$ serum level) were measured using Human Haptoglobin and Human Hemopexin kit products by Cloud Cone Corp. (Katy, TX, USA) by ELISA method at Terpadu Laboratory, Faculty of Medicine, University of Indo. nesia.

Plasma malondialdehyde (MDA) level was obtained at Biochemistry Laboratory of the Faculty of Medicine, University of Indonesia. MDA levels were determined by employing the thiobarbituric acid reaction substance (TBARS) method. The GSH, GSSG, and GSH/GSSG ratio were measured using Microplate Assay for GSH/GSSG kit (Oxford Biomedical Research Inc., Metamora, MI, USA). This antioxidant marker was obtained at Biochemistry Laboratory, Faculty of Medicine, University of Indonesia. The analysis of the $\alpha$-tocopherol levels was measured at the SEAMEO-TROPMED Nutrition Laboratory, Faculty of Medicine, University of Indonesia using the high-performance liquid chromatography method.

\section{Study outcome}

This study aimed to evaluate the effects of $\alpha$-tocopherol in hemolysis and oxidative stress marker on the RBCs membrane in $\beta$-thalassemia major.

\section{Statistical analysis}

All parameters were analyzed using IBM SPSS ver. 22 (IBM Corp., Armonk, NY, USA) The t-test was applied to assess the mean difference between the $\alpha$-tocopherol and placebo groups in a normally distributed data, and the Mann-Whitney test used if the data were not normally distributed. The mean difference between the two groups was statistically significant $(P<0.05)$.

\section{Results}

\section{Enrollment of study participants}

Forty-three patients met the inclusion criteria, but 3 patients did not continue the study because of the failed to comply with the study protocol which is need only 1 month observation. The majority of the thalassemic patients in our center were 2 weeks

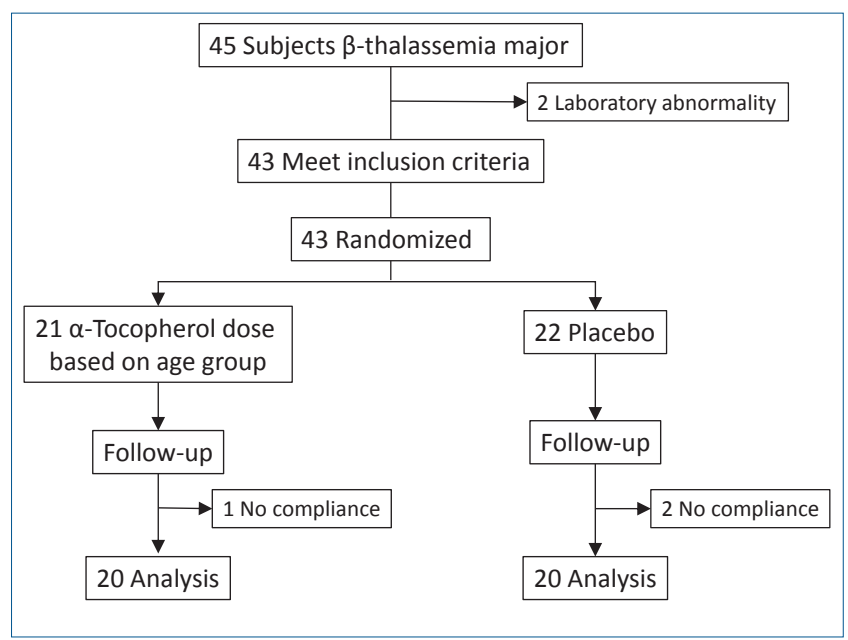

Fig. 1. Subject recruitment scheme.

interval of transfusion, and this became a problem for us for recruiting more subjects. The final subjects were 40 patients, 20 subjects in the placebo group and 20 subjects in the $\alpha$-tocopherol group (Fig. 1).

The characteristics of participants in the 2 study groups, including age, sex, nutritional status (determined by mid-upper arm circumference measurement of World Health Organization criteria), clinical laboratory, hemolysis, oxidative stress, and antioxidant variables before the intervention are presented in Table 1. There was no significant difference in the subject characteristics between the 2 groups.

\section{The effect of $\alpha$-tocopherol on hemolysis marker}

The results of median Hp serum was significantly different between the placebo and the $\alpha$-tocopherol groups $(1.08 \mathrm{mg} / \mathrm{dL}$ and $3.01 \mathrm{mg} / \mathrm{dL}$, respectively; $P=0.021)$. The median relative delta of $\mathrm{Hp}$ level also showed a significant difference between the 2 groups. It was decreased $(-44.15 \%)$ in the placebo group, while it was increased (12.09\%) in the $\alpha$-tocopherol group $(P=0.042)$ (Table 2). The mean level of Hx serum after the intervention showed no difference between the two groups (194.54 $\mathrm{mg} / \mathrm{dL}$ and $180.84 \mathrm{mg} / \mathrm{dL}$, respectively) (Table 2). After the treatment, the mean of RBCs fragility and the mean of delta RBCs fragility also showed no significant difference between the two study groups (Table 2). The result of hemolysis marker in this study indicated that the $\alpha$-tocopherol, as an antioxidant, was significantly effective in improving the hemolysis by increasing the Hp level indirectly.

\section{The effects of a-tocopherol on oxidative stress and antioxi- dant marker}

The results of this study revealed no significant difference in the level of MDA serum between 2 groups (Table 3). The same results also showed in the GSH, GSSG, and GSH/GSSG ratio level, with no significant difference between the 2 groups (Table $3)$. 
Table 1. Subjects' baseline characteristics and clinical laboratory findings

\begin{tabular}{lcc}
\hline Characteristic & Placebo $(\mathrm{n}=20)$ & a-Tocopherol $(\mathrm{n}=20)$ \\
\hline Age $(\mathrm{yr})$ & $11.05 \pm 3.75$ & $12.20 \pm 3.23$ \\
Sex & & $14: 6$ \\
Male:female & & $10: 10$ \\
Nutritional status & $10: 5: 5$ & $9: 8: 3$ \\
Normal:moderate malnutrition:severe malnutrition & $8.25 \pm 0.78$ & $8.13 \pm 0.93$ \\
Hemoglobin $(\mathrm{g} / \mathrm{dL})$ & $22(14-51)$ & $46(12-86)$ \\
Alanine transaminase $(\mathrm{U} / \mathrm{L})$ & $100.50 \pm 15.98$ & $98.30 \pm 16.51$ \\
Total cholesterol $(\mathrm{mg} / \mathrm{dL})$ & $2,451.15 \pm 1,364.92$ & $3,077.45 \pm 2,136.97$ \\
Serum ferritin $(\mathrm{ng} / \mathrm{mL})$ & $76.25 \pm 19.19$ & $76.40 \pm 20.02$ \\
Tansferin saturation $(\%)$ & $1.63(0.66-79.30)$ & $1.71(0.55-78.13)$ \\
Haptoglobin $(\mathrm{mg} / \mathrm{dL})$ & $200.11 \pm 99.54$ & $236.68 \pm 96.19$ \\
Hemopexin $(\mathrm{mg} / \mathrm{dL})$ & $38.74 \pm 13.97$ & $43.36 \pm 12.91$ \\
Red blood cell fragility $(\%)$ & $0.91(0.52-1.69)$ & $1.01(0.52-2.03)$ \\
Malondialdehyde $(\mathrm{nmol} / \mathrm{mL})$ & $11.84(7.04-22.4)$ & $11.84(7.68-18.24)$ \\
GSH $(\mu M)$ & $2.58(1.15-5.73)$ & $2.58(1.34-4.49)$ \\
GSSG $(\mu M)$ & $2.59(1.91-4.15)$ & $2.59(2.07-3.75)$ \\
Rasio GSH/GSSG & $20.26(11.56-68.33)$ & $18.57(12.80-49.59)$ \\
a-Tocopherol $(\mu \mathrm{mol} / \mathrm{L})$ & &
\end{tabular}

Values are presented as mean \pm standard deviation or median (range).

No intergroup difference was observed.

GSH, glutathione; GSSG, oxidized glutathione.

Table 2. Effect of a-tocopherol on hemolysis markers

\begin{tabular}{|c|c|c|c|}
\hline Hemolysis marker & Placebo $(n=20)$ & a-Tocopherol $(n=20)$ & $P$ value \\
\hline \multicolumn{4}{|l|}{ Haptoglobin (mg/dL) } \\
\hline Before, median (range) & $1.63(0.66-79.0)$ & $1.72(0.55-78.13)$ & $0.829^{a}$ \\
\hline After, median (range) & $1.08(0.47-19.78)$ & $3.01(0.60-42.42)$ & $0.021^{\mathrm{a}}$ \\
\hline \multicolumn{4}{|l|}{ Delta of haptoglobin } \\
\hline Absolute (mg/dL), median (range) & $-0.72(-62.9$ to 18.77$)$ & $0.17(-36.96$ to 17.07$)$ & $0.107^{\mathrm{a}}$ \\
\hline Relative (\%), median (range) & $-44.15(-91.99$ to184.42) & 12.09 (-80.17 to 530.07$)$ & $0.042^{\mathrm{a}}$ \\
\hline \multicolumn{4}{|l|}{ Hemopexin (mg/dL) } \\
\hline Before & $200.11 \pm 99.54$ & $236.68 \pm 96.19$ & $0.245^{b}$ \\
\hline After, mean $(95 \% \mathrm{Cl})$ & $194.54(147.23-257.04)$ & $180.84(143.55-227.51)$ & $0.672^{c}$ \\
\hline \multicolumn{4}{|l|}{ Delta of hemopexin } \\
\hline Absolute (mg/dL) & $-26.88 \pm 141.75$ & $-34.99 \pm 82.28$ & $0.100^{b}$ \\
\hline Relative (\%), median (range) & $-5.82(-63.44$ to 227.12$)$ & $-7.22(-58.63$ to 50.95$)$ & $0.117^{\mathrm{a}}$ \\
\hline \multicolumn{4}{|l|}{ RBC fragility (\%) } \\
\hline Before & $38.74 \pm 13.96$ & $43.36 \pm 12.91$ & $0.284^{b}$ \\
\hline After, mean $(95 \% \mathrm{Cl})$ & $39.68(32.27-48.79)$ & $39.28(32.06-48.13)$ & \\
\hline \multicolumn{4}{|l|}{ Delta of RBC fragility (\%) } \\
\hline Absolute & $4.67 \pm 17.74$ & $-0.34 \pm 16.33$ & $0.358^{b}$ \\
\hline Relative, median (range) & $4.96(-46.72$ to 227.28$)$ & $-0.74(-53.39$ to 57.84$)$ & $0.372^{a}$ \\
\hline
\end{tabular}

Values are presented as mean \pm standard deviation unless otherwise indicated.

$\mathrm{RBC}$, red blood cell; $\mathrm{Cl}$, confidence interval.

${ }^{a}$ Mann-Whitney analysis. ${ }^{b} t$ test independent analysis. ${ }^{c} t$ test independent analysis with transformed data, mean geometry, and min-max.

Boldface indicates a statistically significant difference with $P<0.05$.

\section{Discussion}

Our data demonstrated 40 subjects who had completed this study, divided into the placebo and the $\alpha$-tocopherol groups. The results showed no clinically significant difference between the 2 groups in term of the subject's characteristics, hemolysis and oxidative stress marker before the treatment. The mean interval of transfusion was 28 days in all of the subjects, with no significant difference between the 2 groups. It is clinically important showed that the mean level of $\mathrm{Hb}$ in both of groups still below the $\mathrm{Hb}$ pre-transfusion target, which is $9-10.5 \mathrm{~g} /$ $\mathrm{dL}$ as recommended by TIF. ${ }^{14)}$ Serum ferritin and saturation of transferrin were also higher than the standard value, and after intervention showed no significant difference between the 2 
Table 3. Effect of a-tocopherol on oxidative stress and antioxidant markers

\begin{tabular}{|c|c|c|c|}
\hline Oxidative stress and antioxidant & Placebo $(n=20)$ & a-Tocopherol $(n=20)$ & $P$ value \\
\hline \multicolumn{4}{|l|}{$\mathrm{MDA}(\mathrm{nmol} / \mathrm{mL})$} \\
\hline Before & $0.91(0.52-1.69)$ & $1.01(0.52-2.03)$ & $0.203^{a)}$ \\
\hline After & $1.07 \pm 0.31$ & $1.003 \pm 0.34$ & $0.544^{\text {b) }}$ \\
\hline \multicolumn{4}{|l|}{ Delta MDA } \\
\hline Absolute (nmol/mL) & $0.07 \pm 0.37$ & $-0.14 \pm 0.52$ & $0.165^{b)}$ \\
\hline Relative (\%) & $13.98 \pm 36.62$ & $-2.16 \pm 40.29$ & $0.193^{b)}$ \\
\hline \multicolumn{4}{|l|}{$\mathrm{GSH}(\mu \mathrm{M})$} \\
\hline Before & $11.84(7.04-22.40)$ & $11.84(7.68-18.24)$ & $0.377^{\text {a) }}$ \\
\hline After & $6.16(4.58-9.83)$ & $5.81(4.58-11.59)$ & $0.191^{\mathrm{a})}$ \\
\hline \multicolumn{4}{|l|}{ Delta GSH } \\
\hline Absolute $(\mu \mathrm{M})$ & $-5.46(-16.42$ to -2.08$)$ & $-5.68(-12.61$ to 2.17$)$ & $0.914^{\mathrm{a})}$ \\
\hline Relative (\%) & $-46.21 \pm 25$ & $-47.95 \pm 10.97$ & $0.632^{\mathrm{b})}$ \\
\hline \multicolumn{4}{|l|}{ GSSG $(\mu \mathrm{M})$} \\
\hline Before & $2.58(1.15-5.73)$ & $2.58(1.34-4.49)$ & $0.377^{\text {a) }}$ \\
\hline After & $1.86(1.43-2.86)$ & $1.77(1.43-3.34)$ & $0.191^{\mathrm{a})}$ \\
\hline \multicolumn{4}{|l|}{ Delta GSSG } \\
\hline Absolute $(\mu \mathrm{M})$ & $-0.67(-3.92$ to 0.38$)$ & $-0.72(-2.77$ to 0.19$)$ & $0.776^{\mathrm{a})}$ \\
\hline Relative (\%) & $-23.20 \pm 23.92$ & $-25.25 \pm 17.42$ & $0.759^{b)}$ \\
\hline \multicolumn{4}{|l|}{ GSH/GSSG ratio } \\
\hline Before & $2.59(1.9-4.2)$ & $2.59(2.1-3.8)$ & $0.384^{\mathrm{a})}$ \\
\hline After & $1.31(1.20-1.43)$ & $1.29(1.20-1.47)$ & $0.191^{\text {a) }}$ \\
\hline \multicolumn{4}{|l|}{ Delta GSH/GSSG ratio } \\
\hline Absolute & $-1.23(-2.95$ to -0.61$)$ & $-1.30(-2.55$ to -0.79$)$ & $0.291^{\text {a) }}$ \\
\hline Relative (\%) & $-49.18 \pm 9.26$ & $-51.3 \pm 7.59$ & $0.427^{\mathrm{b})}$ \\
\hline
\end{tabular}

Values are presented as mean \pm standard deviation unless otherwise indicated.

$\mathrm{RBC}$, red blood cell; $\mathrm{Cl}$, confidence interval.

${ }^{a)}$ Mann-Whitney analysis. ${ }^{\mathrm{b}} t$ test independent analysis. ${ }^{\mathrm{c}} t$ test independent analysis with transformed data, mean geometry, and min-max.

Boldface indicates a statistically significant difference with $P<0.05$.

groups.

The mean level of $\mathrm{Hp}$ as a hemolysis marker showed a significant increase in the $\alpha$-tocopherol group, although the Hp level did not reach the normal limit $(P=0.04)$. Thus, it suggested meaningful implications for the therapeutic use of the $\alpha$-tocopherol for oxidative stress on the RBCs membrane, which can lead to progressive hemolysis. This data demonstrated that the $\alpha$-tocopherol could improve hemolysis by the increasing of $\mathrm{Hp}$ level.

As the plasma Hp level is decreased in hemolysis as well as in the presence of ineffective erythropoiesis, its depletion is a reliable marker for the instant diagnosis of accelerated RBCs destruction. In $\beta$-thalassemia, abnormally high levels of oxidative stress account for accelerated senescence and increased the destruction of erythrocytes. ${ }^{3)}$ Ragab et al. ${ }^{17)}$ stated that thalassemia children had more severe Hp depletion compared to healthy subjects and all of the thalassemic children had their Hp level less than $12 \mathrm{mg} / \mathrm{dL}$. Similar to our study, hemolysis and ineffective erythropoiesis in $\beta$-thalassemia major leads to $\mathrm{Hp}$ depletion and related to the severity of hemolysis.

The normal value for hemopexin level in children is $77 \mathrm{mg} /$ $\mathrm{dL}$ (range, $66-100 \mathrm{mg} / \mathrm{dL}$ ) in average. ${ }^{4}$ Both of groups showed an increased average level of $\mathrm{Hx}$ serum than normal value after the treatment $(194.54 \mathrm{mg} / \mathrm{dL}$ and $180.84 \mathrm{mg} / \mathrm{dL}$ ) in the placebo and the $\alpha$-tocopherol group respectively, and no significant difference was found. Hemopexin can bind to heme as a product of free $\mathrm{Hb}$ from hemolysis process with high affinity. ${ }^{5)}$ Decreased levels of $\mathrm{Hx}$ have been noted in chronic and severe hemolytic states. On the contrary, Hx levels can increased in the acute-phase response, ${ }^{18)}$ from our data there were no increased of leukocyte count in both of 2 groups and we didn't identify other factors associated with elevated of $\mathrm{Hx}$ levels involved in the inflammation process.

Cutillo et al. ${ }^{19)}$ demonstrated that out of 45 thalassemia major cases, $\mathrm{Hp}$ level was absent $(\mathrm{Hp} 0)$ in 13 subjects and $\mathrm{Hx}$ level was also absent $(\mathrm{Hx} 0)$ in 37 subjects. It has been stated that $\mathrm{Hx}$ depletion depends on the high concentration of free heme and decreased or absent of $\mathrm{Hx}$ also leads to very severe hemolysis. However, there are few data available for patients with $\beta$-thalassemia.

In this current study, we found no significant decrease in the $\mathrm{Hx}$ level. This finding may be influenced by the role of $\mathrm{Hp}$-free and $\mathrm{Hb}$ complex. Therefore, $\mathrm{Hp}$ can protect $\mathrm{Hb}$ form oxidative modifications that would otherwise prevent its results in the release of free heme to the circulation. ${ }^{20)}$ We assumed that the $\alpha$-tocopherol has indirectly benefited for increasing of $\mathrm{Hp}$ level by neutralizing lipid peroxidation and preventing hemolysis. Unlike other studies, we found a higher mean of the Hx level 


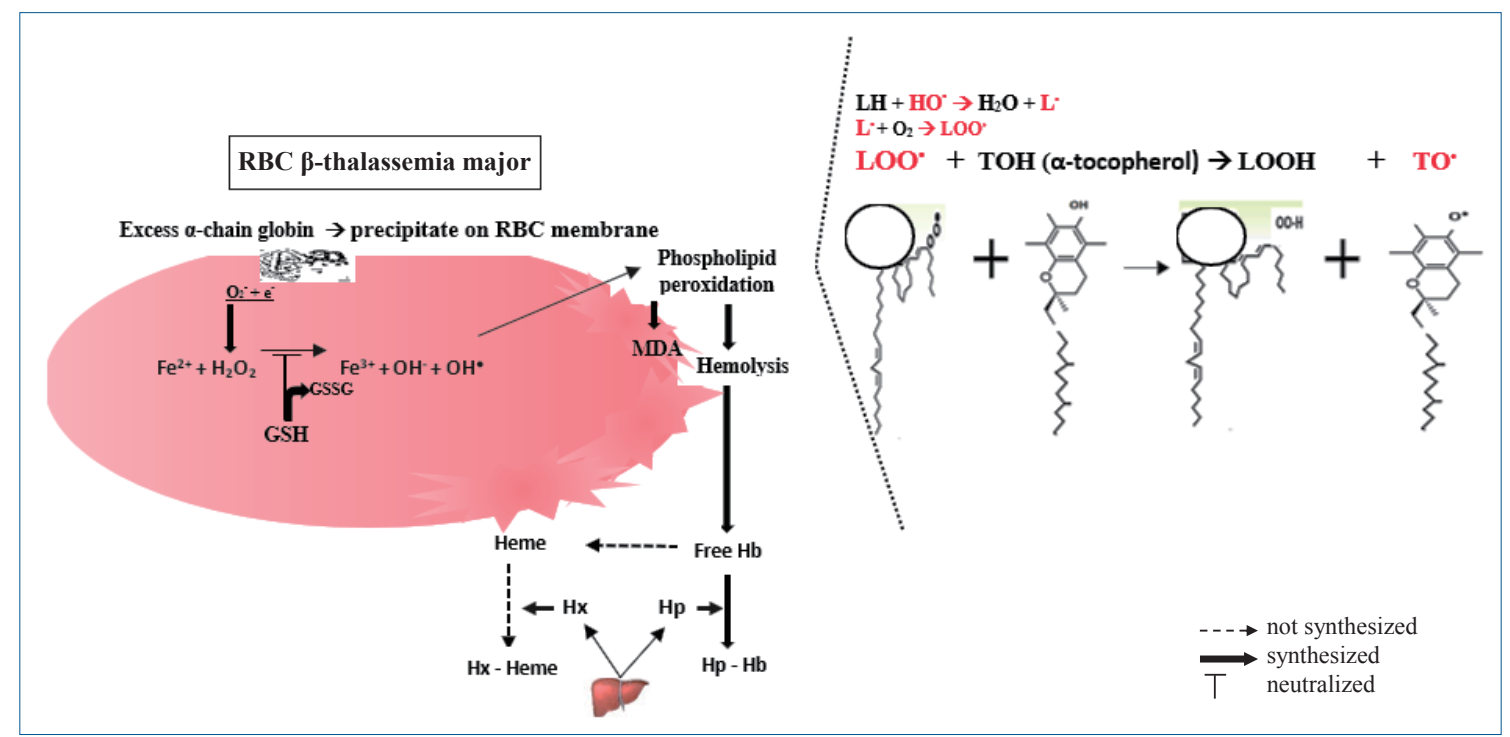

Fig. 2. Suggested a-tocopherol mechanism on hemolysis and oxidative stress in red blood cell (RBC) membranes of patients with $\beta$ -thalassemia major. GSSG, oxidized glutathione; GSH, reduced glutathione; MDA, malondialdehyde; Hb, hemoglobin; Hx, hemopexin; $\mathrm{Hp}$, haptoglobin; $\mathrm{LOO}^{\circ}$, lipid peroxide radicals; TOH, alpha-tocopherol; $\mathrm{LOOH}$, lipid hydroxyperoxyde; TO, tocopheroxyl radicals.

than the normal value. The increasing Hx level may be due to the $\mathrm{Hx}$ as an acute-phase reactant in the inflammatory process, but we did not investigate the inflammation marker and viral load. Hence, it should be examined in the future research.

The percentage lysis of RBCs was slightly decreased in the $\alpha$-tocopherol group, but there was no significant difference between the two study groups. In thalassemia patients with transfusion-dependent, the RBCs membrane integrity appears to be destroyed, with the loss of essential polarity and fluidity gradient and oxidative stress by lipid peroxidation may induce membrane fragility and hemolysis. ${ }^{21)}$ We suggested that the $\alpha$-tocopherol is considered to be able to protect RBCs membrane and reduce hemolysis.

After the treatment, the MDA level showed no significant difference between the groups, we assumed that influenced by only short-term period of study and oxidative stress still exist. MDA, the product of lipid peroxidation, is generated in excessive amounts, supporting the fact that large quantities of membranebound iron are present in thalassemia RBCs. ${ }^{22,23)}$

Several studies have shown that MDA is a marker to determine the existence of oxidative stress. ${ }^{24-26)}$ Mahjoub et al. ${ }^{9}$ ) and Das et al. ${ }^{27)}$ stated that MDA level decreased significantly in thalassemia patients who received the $\alpha$-tocopherol. We found different results in our study. The contrary finding may be due to the different subjects' characteristic, sample sizes, and study protocols.

The ratio between endogen antioxidant (GSH), GSSG, and GSH/GSSG also indicated no significant difference between the 2 study groups. GSH is oxidized to form GSSG, which can be reduced to GSH by the NADPH-dependent GR. ${ }^{28)}$ The GSH/ GSSG ratio reflects the oxidative state and it interacts with redox couples to maintain the appropriate redox balance in the cells. ${ }^{29)}$ Therefore, the lower ratio of GSH/GSSG may indicate higher oxidative stress in cells. ${ }^{10)}$ Mahdi3 ${ }^{30)}$ and Qaiser et al. ${ }^{31)}$ reported the lower levels of GSH in $\beta$-thalassemia major compared to healthy subjects $(P<0.01)$. This study also revealed no significant difference in GSH, GSSG and GSH/GSSG ratio between 2 study groups.

This study revealed that there was a decrease in the $\alpha$-tocopherol level in thalassemic children before the treatment. Previous studies showed low levels of the $\alpha$-tocopherol which can be explained by the excessive iron fraction generated by a lipid peroxidation process with subsequent antioxidant consumption. ${ }^{22,32,33)}$ In this study, we did not performed a special form for recording the clinically adverse event. Moreover, there was no case reported by the subjects in this study, such as the disturbance of gastrointestinal and bleeding due to oral supplementation of the $\alpha$-tocopherol.

\section{The suggestion of the a-tocopherol mechanism on hemoly- sis and oxidative stress in RBCs membrane $\beta$-thalassemia major}

In this study, we proposed the mechanism of GSH and $\alpha$ tocopherol to neutralize free radical, reducing hemolysis and oxidative stress on the RBC membrane by (Fig. 2): (1) Endogen antioxidant (GSH and GSSG): the reaction of GSH and hy. drogen peroxide $\left(\mathrm{H}_{2} \mathrm{O}_{2}\right)$ can inhibit hydroxyl radical $\left(\mathrm{OH}_{\bullet}\right)$ as oxidant molecule. (2) Exogen antioxidant ( $\alpha$-tocopherol): the $\alpha$-tocopherol serves as a chain breaker and neutralizes lipid peroxyl radical during the lipid peroxidation in RBCs membranes. (3) Alpha-tocopherol may neutralize hydroxyl radicals $(\mathrm{OH} \bullet)$, but it assumed that $\alpha$-tocopherol is not an efficient scavenger for hydroxyl radicals.

In conclusion, the $\alpha$-tocopherol as an antioxidant has an important effect in RBCs membrane for reducing hemolysis, by indirectly increasing the level of $\mathrm{Hp}$ in $\beta$-thalassemia major. Endogenous antioxidant was not affected by $\alpha$-tocopherol supplementation. 


\section{Suggestion}

Further research using similar study protocols is necessary to investigate the hemolysis marker and oxidative stress for those having transfusion every 2 weeks and pretransfusion $\mathrm{Hb}$ between 9 to $10.5 \mathrm{~g} / \mathrm{dL}$ for longer study period. We also suggest a study to identify marker inflammation in case with elevated of $\mathrm{Hx}$ in thalassemic patient.

\section{Conflicts of interest}

No potential conflict of interest relevant to this article was reported.

\section{Acknowledgements}

This study was supported by Indonesia Endowment Fund for Education (LPDP).

\section{References}

1. Fibach E, Rachmilewitz EA. Pathophysiology and treatment of patients with beta-thalassemia: an update. F1000Res 2017;6:2156.

2. Kwiatkowski JL. Hemoglobinopathies. In: Lanzkowsky P, Lipton JM, Fish JD, editors. Lanzkowskys's manual of pediatric hematology and oncology. 6th ed. London: Elsevier, 2016:166-96.

3. Voskou S, Aslan M, Fanis P, Phylactides M, Kleanthous M. Oxidative stress in $\beta$-thalassaemia and sickle cell disease. Redox Biol 2015;6:226-39.

4. Smith A, McCulloh RJ. Hemopexin and haptoglobin: allies against heme toxicity from hemoglobin not contenders. Front Physiol 2015;6:187.

5. Schaer CA, Deuel JW, Bittermann AG, Rubio IG, Schoedon G, Spahn $\mathrm{DR}$, et al. Mechanisms of haptoglobin protection against hemoglobin peroxidation triggered endothelial damage. Cell Death Differ 2013;20: 1569-79.

6. Körmöczi GF, Säemann MD, Buchta C, Peck-Radosavljevic M, Mayr WR, Schwartz DW, et al. Influence of clinical factors on the haemolysis marker haptoglobin. Eur J Clin Invest 2006;36:202-9.

7. Schaer DJ, Vinchi F, Ingoglia G, Tolosano E, Buehler PW. Haptoglobin, hemopexin, and related defense pathways-basic science, clinical perspectives, and drug development. Front Physiol 2014;5:415.

8. Chow J, Phelan L, Bain BJ. Evaluation of single-tube osmotic fragility as a screening test for thalassemia. Am J Hematol 2005;79:198-201.

9. Mahjoub S, Tamadoni A, Zanjanchi NM, Moghadamnia AA. The effects of beta-carotene and vitamin $\mathrm{E}$ on erythrocytes lipid peroxidation in betathalassemia patients. J Res Med SCI 2007;12:301-7.

10. Kalpravidh RW, Tangjaidee T, Hatairaktham S, Charoensakdi R, Panichkul N, Siritanaratkul N, et al. Glutathione redox system in $\beta$ thalassemia/Hb E patients. ScientificWorldJournal 2013;2013:543973.

11. Lawson M, Jomova K, Poprac P, Kuča K, Musílek K, Valko M. Free radicals and antioxidants in human disease. In: Al-Gubory KH, Laher I, editors. Nutritional antioxidant therapies: treatment and perspectives. Basel: Springer International, 2017:283-305.

12. Srichairatanakool S, Fucharoen S. Antioxidants as complementary medication in thalassemia. In: Atroshi F, editor. Pharmacology and nutritional intervention in the treatment of disease. London: InTech, 2014:119-58.

13. Attia MM, Sayed AM, Ibrahim FA, Mohammed AS, El-Alfy MS. Effects of antioxidant vitamins on some hemoglobin properties and erythrocytes in homozygous beta-thalassemia. Romanian J Biophys 2011;21:116.
14. Angastinotis M. Lifestyle and quality of life. In: Capellini MD, Porter J, Taher A, Viprakasit V, editors. Guidelines for management of transfusion dependent thalassemia (TDT). 3rd ed. Cyprus: Thalassemia International Foundation, 2014:224-35.

15. Vichinsky E, Levine L, Bhatia S, Bojanowski J, Coates T. Standards of care guidelines for thalassemia. Oakland: Children's Hospital and Research Centre Oakland, 2012:1-14.

16. Amelia N, Amalia P, Windiastuti E, Lubis B. Thalassemia. In: Pudjiadi AP, Hegar B, Handryastuti S, Idris NS, Gandaputra EP, Harmoniati ED, editors. Pedoman pelayan medis. Jakarta: Ikatan Dokter Anak Indonesia, 2009:299-302.

17. Ragab SM, Safan MA, Badr EA. Study of serum haptoglobin level and its relation to erythropoietic activity in Beta thalassemia children. Mediterr J Hematol Infect Dis 2015; 7:e2015019.

18. Rother RP, Bell L, Hillmen P, Gladwin MT. The clinical sequelae of intravascular hemolysis and extracellular plasma hemoglobin: a novel mechanism of human disease. JAMA 2005;293:1653-62.

19. Cutillo S, Meloni T. Serum concentrations of haptoglobin and hemopexin in favism and thalassemia. Acta Haematol 1974;52:65-9.

20. Thomsen JH, Etzerodt A, Svendsen P, Moestrup SK. The haptoglobinCD163-heme oxygenase-1 pathway for hemoglobin scavenging. Oxid Med Cell Longev 2013;2013:523652.

21. Freisleben SK, Hidayat J, Freisleben HJ, Poertadji S, Kurniawan B, Bo NP, et al. Plasma lipid pattern and red cell membrane structure in $\beta$-thalassemia patients in Jakarta. Med J Indones 2011;20:178-84.

22. Ghone RA, Kumbar KM, Suryakar AN, Katkam RV, Joshi NG. Oxidative stress and disturbance in antioxidant balance in beta thalassemia major. Indian J Clin Biochem 2008;23:337-40.

23. Zhong S, Yin H. Lipid peroxidation: role of vitamin E. In: Niki E, editor. Chemistry and nutritional benefits. Cambridge: The Royal Society of Chemistry, 2019:118-133.

24. Giardini O, Cantani A, Donfrancesco A, Martino F, Mannarino O, D'Eufemia P, et al. Biochemical and clinical effects of vitamin $\mathrm{E}$ administration in homozygous beta-thalassemia. Acta Vitaminol Enzymol 1985; 7:55-60.

25. Laksmitawati DR, Handayani S, Udyaningsih-Freisleben SK, Kurniati V, Adhiyanto C, Hidayat J, et al. Iron status and oxidative stress in betathalassemia patients in Jakarta. Biofactors 2003;19:53-62.

26. Bhagat SS, Sarkar PD, Suryakar AN, Padalkar RK, Karni AC, Ghone RA, et al. A study on the biomarkers of oxidative stress: the effects of oral therapeutic supplementation on the iron concentration and the product of lipid peroxidation in beta thalassemia major. J Clin Diagn Res 2012;6:1144-7.

27. Das N, Das Chowdhury T, Chattopadhyay A, Datta AG. Attenuation of oxidative stress-induced changes in thalassemic erythrocytes by vitamin $\mathrm{E}$. Pol J Pharmacol 2004;56:85-96.

28. Wu G, Fang YZ, Yang S, Lupton JR, Turner ND. Glutathione metabolism and its implications for health. J Nutr 2004;134:489-92.

29. Ribas V, García-Ruiz C, Fernández-Checa JC. Glutathione and mitochondria. Front Pharmacol 2014;5:151.

30. Mahdi EA. Relationship between oxidative stress and antioxidant status in beta thalassemia major patients. Acta Chim Pharm Indica 2014;4:137-45.

31. Qaiser S, Hoque MZ, Iqbal M, Mudin DK. Evaluation of antioxidant status in beta thalassemia major patients in Sabah, Malaysian Borneo. Biores Commun 2015;1:45-7.

32. Sherief LM, Abd El-Salam SM, Kamal NM, El Safy O, Almalky MA, Azab SF, et al. Nutritional biomarkers in children and adolescents with Beta-thalassemia-major: an Egyptian center experience. Biomed Res Int 2014;2014:261761.

33. Westergren T, Kalikstad B. Dosage and formulation issues: oral vitamin E therapy in children. Eur J Clin Pharmacol 2010;66:109-18. 